\title{
Optimization of Powder Spray Process Parameters using Taguchi Methodology
}

\author{
S. Karidkar ${ }^{1}$, R. Mali $^{2}$ \\ ${ }^{1}$ Asstistat Professor, ${ }^{2} \mathrm{PG}$ Student, KIT’s College of Engineering, Kolhapur, India \\ \{skaridkar@gmail.com\}
}

\begin{abstract}
Powder coating of metal product is essential to avoid corrosion and to improve surface properties. The coating thickness alone doesn't ensure the corrosion resistance. If surface is not covered completely, the microgaps can initiate rusting. Hence, microstructures should be observed for various coating thicknesses. This study aims to study the effect of powder coating parameters (gun stand-off distance and gun traverse speed) on coating thickness and microstructure. First, the range of process parameters in which desired values of coating thickness is found and then second experiment is carried out to optimize the powder spray process parameters. The experimental investigation is done using DoE, Taguchi design, $\mathrm{L}_{16}$ orthogonal array. Obtained experimental results were analyzed using Minitab 16, statistical software, to study the effect of process parameters on response variables. To understand the effect of process parameters, the main effects, interaction and contour plots are obtained. The ANOVA results were studied to understand significance of process parameters on coating thickness. The results also show that F-value for gun stand-off distance is much higher than that of gun traverse speed. Hence, the gun stand-off distance is major parameter affecting coating thickness. The microstructure studies were carried out to see uncoated gaps for various combinations of process parameters. Powder coating at very close distance and at low gun speeds results in excess coating thickness and uneven surface structure. The second experiment was conducted to optimize process parameters.
\end{abstract}

Keywords:Powder coating, coating thickness, coating microstructure, Taguchi Methodology

\section{Introduction}

The primary application of powder spray coatings is for surface enhancement of different products to improve properties such as scratch resistance, corrosion resistance, etc. Thus, in all applications coat quality formed during powder coating is very important. Coating thickness is an important parameter as excess deposition of powder will increase material coat \& low thickness will lead to exposure to atmosphere and consequently corrosion, rusting. All these reasons lead to need for study of coating thickness. So the various parameters that affect coating thickness are studied and two parameters viz. gun stand-off distance and gun traverse speed are chosen and experiments are conducted[Fig.1].

\section{Objectives}

1. To investigate the effect of stand-off distance and gun traverse speed on powder coating thickness and microstructure of coating.

2. To find optimum values of gun traverse speeds and gun stand-off distance for desired coating thickness range.

\section{Literature review}

Dastoori [1] discusses the effect of different variables on powder thickness and adhesion of two types of guns, corona and tribo. They found the adhesion values is maximum when nozzle is perpendicular to substrate.

B. Iyer, S. Nalbalwar and R. Pawade (Eds.)

ICCASP/ICMMD-2016. Advances in Intelligent Systems Research.

Vol. 137, Pp. 71-76.

(C) 2017. The authors - Published by Atlantis Press

This is an open access article under the CC BY-NC license (http://creativecommons.org/licens)es/by-nc/4.0/)

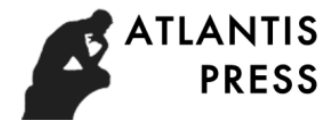


The build-up of the powder reaches to maximum in 6-8 seconds. Shah [2] reports work on the gas and powder particle flow patterns for various operating conditions and developed a numerical model to optimize the powder

booth design. Effect of reducing particle size on the coating is also considered. They found that the inability of powder coating to provide a very smooth and glossy finish surface when $30 \mu \mathrm{m}$ or bigger size particles are used.

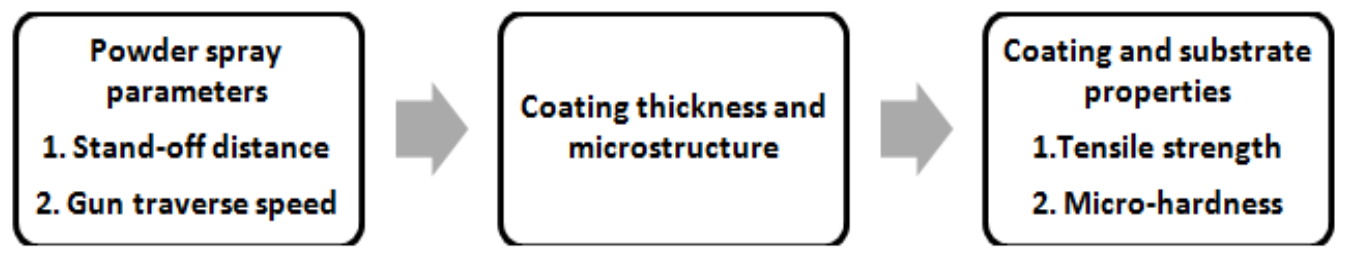

Fig. 1.Conceptual Framework for Process Parameters \& Response Variables

Jacques Cazaux [3] finds that thickness of the charged powder layer is limited in two ways. For these limits, analytical expressions are found to understand role of particle size and dielectric constant of powder to the role of thickness, structure, and dielectric constant of the insulating substrate. W. Y. Li [4] study the effect of standoff distance (distance between nozzle exit \& substrate) on coating deposition characteristics and found that correct stand-off distance for maximum powder deposition efficiency varies with particle velocity. Also it affects coating thickness formed. Xiangbo Meng [5] in their work reveals that the coarse powder gives higher coating efficiency than the ultrafine powder. The powder spray distribution is even for ultrafine powder and concave for coarse powder.

Literature review shows that the powder coating properties-coating thickness, coating porosity, scratch resistance, tensile strength of substrate and coating, are influenced by many parameters. The main parameters affecting are nozzle-substrate stand-off distance, coating time/gun traverse speed, position of gun, particle size of powder, particle velocity, gun air pressure and temperature, nozzle dimensions, type of gas. The various findings are taken into consideration for this project and used during design of experiment. The factors are kept constant and values are as follows:

1. Gun voltage $=100 \mathrm{KV}$

2. Gun air pressure $=1.5$ bar

3. Position of gun $=$ Normal to substrate surface

4. Powder $=$ Epoxy-polyster thermosetting powder

5. Powder state $=$ Dry powder

6. Moisture in booth air $=$ Normal atmospheric conditions

\section{Experimental Procedure}

\subsection{Design of experiments using Taguchi methodology}

The experimental investigation of optimal parameters was done using DoE, Taguchi methodology, $\mathrm{L}_{16}$ orthogonal array in MINITAB software. Two parameters along with their levels are shown in Table 1 and 2. The results obtained through the screening experiment are used to optimize the process parameters in the final experiment. 
Table 1 Powder spray process parameters and their levels for screening experiment

\begin{tabular}{|c|c|c|c|c|c|}
\hline \multirow{2}{*}{ Sr. No. } & \multirow{2}{*}{ Process parameters } & \multicolumn{4}{|c|}{ Levels } \\
\cline { 3 - 6 } & & I & II & III & IV \\
\hline 1 & Gun traverse speed $(\mathrm{mm} / \mathrm{sec})$ & 15 & 25 & 35 & 45 \\
\hline 2 & Gun stand-off distance $(\mathrm{mm})$ & 100 & 200 & 300 & 400 \\
\hline
\end{tabular}

Table 2 Powder spray process parameters and their levels for final experiment

\begin{tabular}{|c|c|c|c|c|c|}
\hline \multirow{2}{*}{ Sr. No. } & Process parameters & \multicolumn{4}{|c|}{ Levels } \\
\cline { 3 - 6 } & & I & II & III & IV \\
\hline 1 & Gun traverse speed $(\mathrm{mm} / \mathrm{sec})$ & 15 & 25 & 35 & 45 \\
\hline 2 & Gun stand-off distance $(\mathrm{mm})$ & 220 & 240 & 260 & 280 \\
\hline
\end{tabular}

To perform the experiment as per design, the setup is manufactured as shown in following Fig. 2. The setup consists of a platform on which the powder spray gun is placed. The platform movement depends upon the movement of leadscrew. The leadscrew is connected to a DC motor through belt drive. The speed of DC motor is controlled through the electronic controller. The guideways are provided for gun platform. The specimen holders are provided to the front side of the spray gun, with the arrangement to change the stand-off distance between spray gun and specimen.

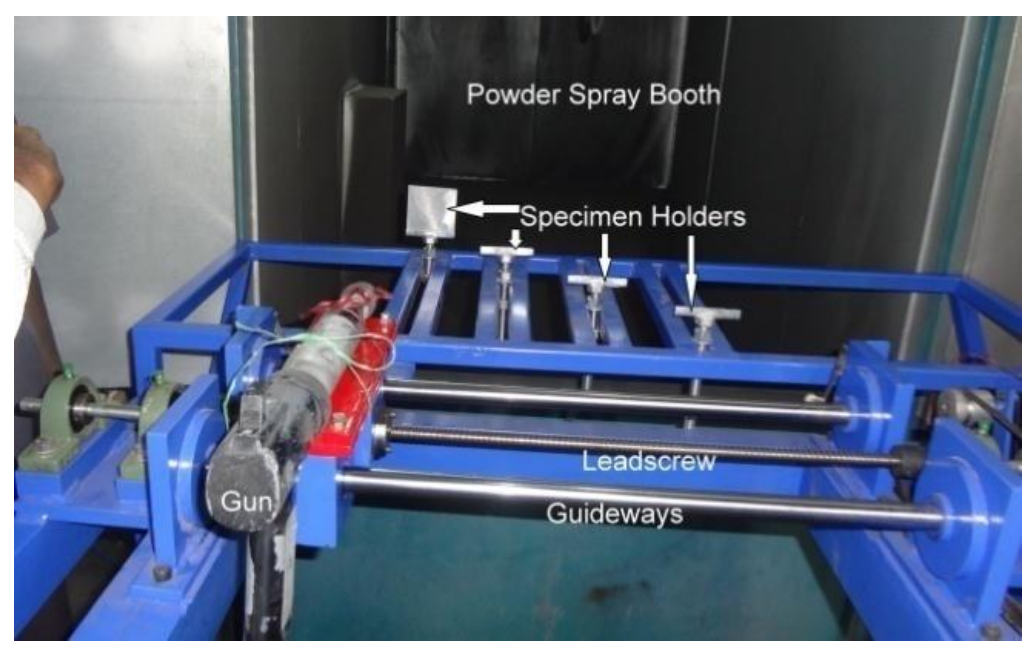

Fig. 2. Powder spray experiment setup

\subsection{Preparation of specimen}

As per Taguchi Design, 16 specimens were cleaned with chemical pretreatment and allowed to dry. Then the specimen were mounted on specimen holder and sprayed. The photos were taken for purpose of visual inspection. Further the specimens are kept in oven for curing of powder and allowed to cool. The thickness of coatings was measured by thickness gauge. The notations on the following photos indicate gun traverse speed and gun stand-off distance at which the powder is sprayed on specimen. For example, 15-100 indicates that the specimen is sprayed at $15 \mathrm{~mm} / \mathrm{sec}$ and at $100 \mathrm{~mm}$ stand-off distance.

\section{Results and Discussion}

\subsection{Visual inspection of specimens coating}

The powder sprayed specimens were inspected after powder spraying and before curing. Powder fall was observed for the specimen placed at distance less than $200 \mathrm{~mm}$ and at very low gun traverse speed that is 15 and $25 \mathrm{~mm} / \mathrm{sec}$ [Fig. 3]. The powder falls down as it fails to get attracted towards the specimen. The reason behind is 
that the first deposited layer repels further layers powder trying to deposit on surface of specimen. This results and reasons are supported in by Jacques Cazauxs' research[3].
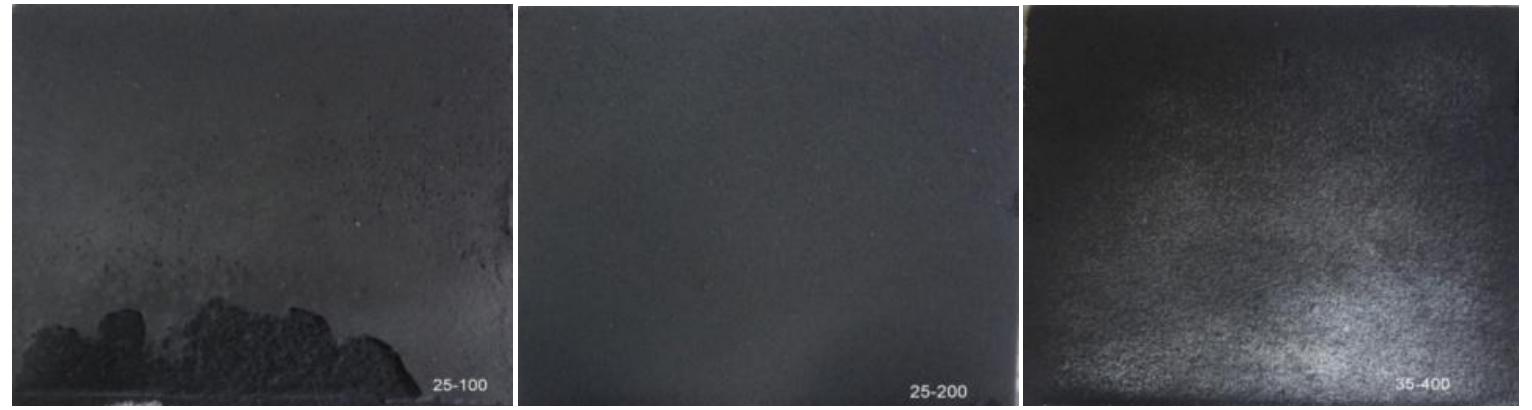

Fig. 3. Powder sprayed specimens: Left Fig. shows fall of powder, middle Fig. shows uniform powder spray and right most Fig. shows insufficient powder coverage. First number indicates gun traverse speed and second number indicates gun stand-off distance.

It is also observed that at $400 \mathrm{~mm}$ stand-off distance, the powder doesn't cover whole surface of specimen. This will further cause exposure to the atmosphere and purpose of coating will fail. The reason behind this is that powder particles follow downward trajectory direction, instead straight path, due to gravity. The detailed work is carried by Shah [2], supporting the path of powder particles follow. All the specimens with stand-off distance at 200 and $300 \mathrm{~mm}$ are coated neatly. For the final experiment, stand-off distances for all specimens are kept between 200 to $300 \mathrm{~mm}$. The uniform powder coating was observed within this range.

\subsection{Coating Thickness}

The Minitab 16 results for coating thickness indicates that the stand-off distance less than 200 mm causes excess coating thickness. The stand-off distance more than $300 \mathrm{~mm}$ causes insufficient coating thickness. The main effects plots [Fig. 4] show that the effect of gun stand-off distance is more significant on coating thickness, as the slope of gun stand-off distance is much higher than that of the gun traverse speed. The process parameters viz., gun stand-off distance and gun traverse speed do not show any interaction [Fig. 5]. The final experiment carried. The contour plot is obtained [Fig.6]. For the desired coating thickness of 50 to 100 microns, the gun traverse speed can be varied from $32 \mathrm{~mm} / \mathrm{sec}$ to $45 \mathrm{~mm} / \mathrm{sec}$ and the stand-off distance can be kept between 220 $\mathrm{mm}$ to $270 \mathrm{~mm}$. There are more points for gun speed less than $32 \mathrm{~mm} / \mathrm{sec}$ that gives desired coating thickness, but keeping gun speed less than $32 \mathrm{~mm} / \mathrm{sec}$ doesn't assure within range thickness.

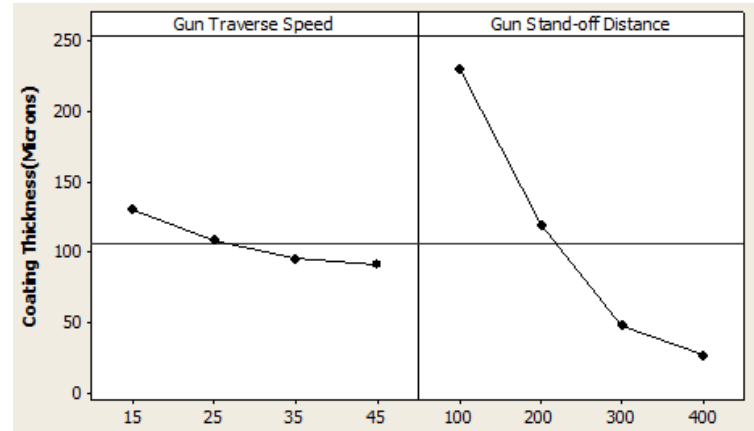

Fig. 4. Main effects plots for coating thickness versus gun traverse speed, gun stand-off

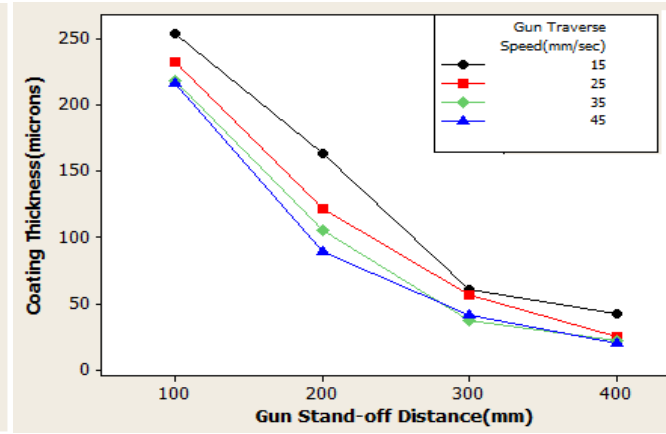

Fig. 5. Interaction plots for coating thickness versus gun traverse speed, gun stand-off distance

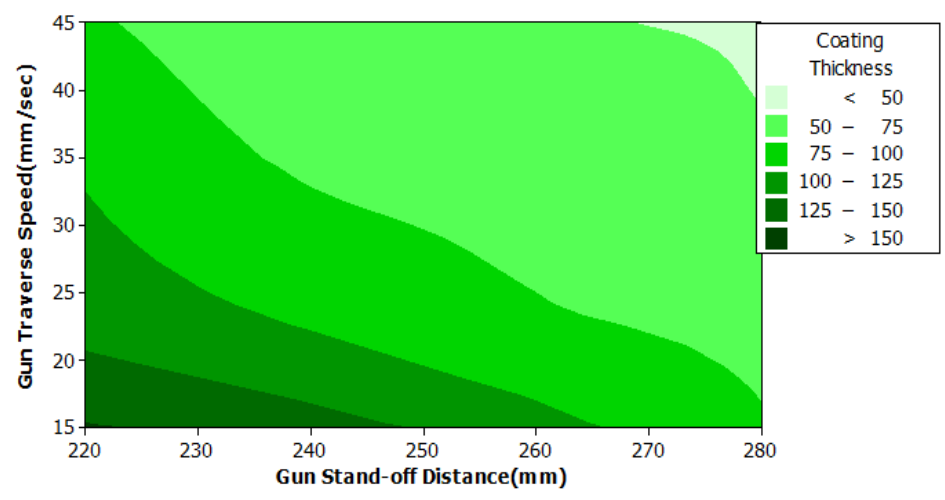

Fig. 6. Contour plot of coating thickness 


\subsection{ANOVA results}

The ANOVA results (Table 3) from screening experiment shows that the p-value for gun stand-off distance is zero and p-value for gun traverse speed is much lower than 0.05 . This indicates that the both process parameters (gun stand-off distance \& gun traverse speed) are significant while calculating coating thickness. The results also show that F -value for gun stand-off distance is much higher than that of gun traverse speed. Hence, the gun stand-off distance is major parameter affecting coating thickness. The ANOVA results (Table 4) for final experiment also showed similar results for $\mathrm{p}$-value, but the $\mathrm{F}$ value for is gun traverse speed is higher than gun stand-off distance.

Table 3 ANOVA results for for screening experiment

\begin{tabular}{|l|c|c|c|c|c|c|}
\hline \multicolumn{1}{|c|}{ Source } & DF & Seq SS & Adj SS & Adj MS & F & P \\
\hline Gun Traverse Speed & 3 & 3566 & 3566 & 1189 & 9.98 & 0.003 \\
\hline Gun Stand-off Distance & 3 & 100289 & 100289 & 33430 & 280.59 & 0.000 \\
\hline Error & 9 & 1072 & 1072 & 119 & & \\
\hline Total & 15 & 104928 & & & & \\
\hline S =10.9151 R-Sq =98.98\% R-Sq(adj) $=98.30 \%$ \\
\hline
\end{tabular}

Table 4 ANOVA results for final experiment

\begin{tabular}{|l|l|l|l|l|l|l|}
\hline \multicolumn{1}{|c|}{ Source } & DF & Seq SS & Adj SS & Adj MS & F & P \\
\hline Gun Traverse Speed & 3 & 7637.2 & 7637.2 & 2545.7 & 28.14 & 0.000 \\
\hline Gun Stand-off Distance & 3 & 5109.7 & 5109.7 & 1703.2 & 18.83 & 0.000 \\
\hline Error & 9 & 814.1 & 814.1 & 90.5 & & \\
\hline Total & 15 & 13560.9 & & & & \\
\hline S =9.51059 R-Sq $=94.00 \%$ & R-Sq(adj) $=90.00 \%$ \\
\hline
\end{tabular}

\subsection{Coating microstructure}

From microstructures in screening experiment, it was observed that the specimen surfaces were entirely covered with the powder for the specimens with stand-off distances of 100, $200 \& 300 \mathrm{~mm}$, whereas the specimen coated with $400 \mathrm{~mm}$ stand-off distance shows gaps at 50x photographs [Fig. 7]. The 450x photographs show clearly that larger portion of the specimen at $400 \mathrm{~mm}$ stand-off distance is not covered by the powder. Though the microstructure for specimen at $100 \mathrm{~mm}$ shows full coverage, it's not uniform. The microstructure for specimen with stand-off distance of 200 and $300 \mathrm{~mm}$ show uniform structure of powder over the surface.
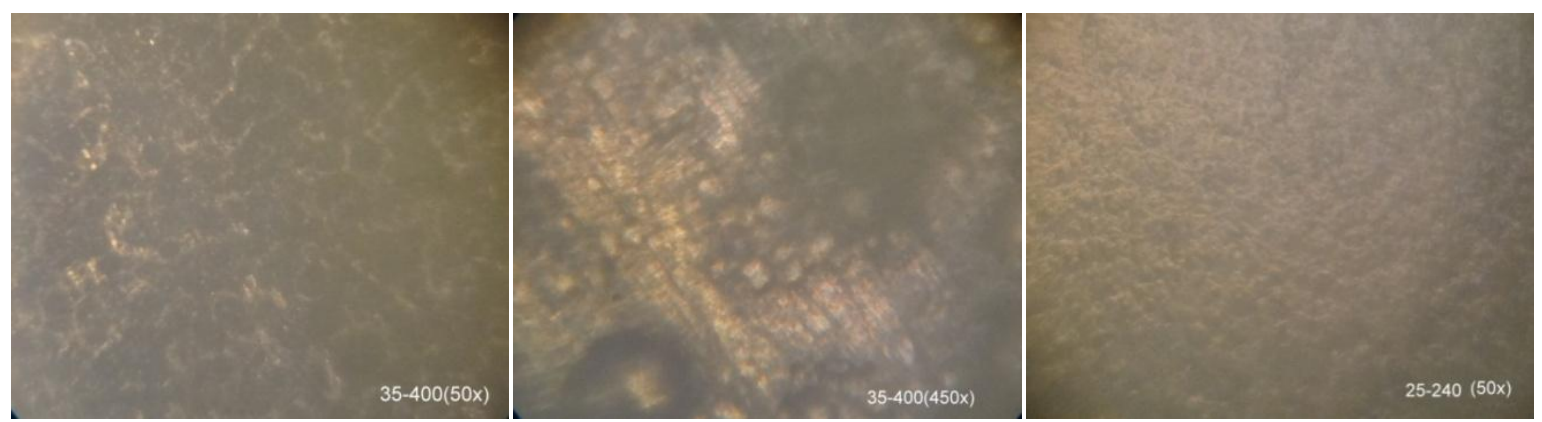

Fig. 7. Microstructures: Left Fig. shows lines that indicates insufficient coverage, which is clearly seen in middle Fig. and right most Fig. shows uniformly cured powder surface. First number indicates gun traverse speed and second number indicates gun stand-off distance. 


\section{Conclusions}

The research was aiming to optimize powder spray process parameters (gun stand-off distance and gun traverse speed). Their effect on coating thickness and microstructures were studied. ANOVA results showed that both parameters are significant for the desired coating thickness. For very low gun speeds and short stand-off distances, powder falls down due to maximum thickness limit. Main effects plots, interaction plots and contour plots obtained from both experiments showed that the desired range of coating thickness (50 to 100 microns), and uniform microstructure, is obtained between 220 to $270 \mathrm{~mm}$ of stand-off distance with gun traverse speed varying from $32 \mathrm{~mm} / \mathrm{sec}$ to $45 \mathrm{~mm} / \mathrm{sec}$.

\section{References}

[1]. K. Dastoori, B. Makin, G.L. Tan K., "Measurement of the electrostatic powder coating properties for corona and triboelectric coating guns", Journal of Electrostatics, 63 (2005) 545-550

[2]. U. Shah, C. Zhang, J. Zhu, "Comparison of electrostatic fine powder coating and coarse powder coating by numerical simulations", Journal of Electrostatics, 64 (2006) 345-354

[3]. Jacques Cazaux, "Critical thicknesses of electrostatic powder coatings from inside", Journal of Electrostatics, 65 (2007) 764-774

[4]. W.-Y. Li, C. Zhang, X.P. Guo, G. Zhang, H.L. Liao, C.-J. Li, C. Coddet, "Effect of standoff distance on coating deposition characteristics in cold spraying", Materials and Design, 29 (2008) 297-304

[5]. Xiangbo Meng, "Influences of different powders on the characteristics of particle charging and deposition in powder coating processes", Journal of Electrostatics, 67 (2009) 663-671 